\title{
Fritz Scholz-a tribute on the occasion of his 65th birthday
}

\author{
Antonio Doménech-Carbó ${ }^{1} \cdot$ György Inzelt ${ }^{2}$ (i)
}

Received: 15 April 2020 /Revised: 22 April 2020 / Accepted: 23 April 2020 / Published online: 8 May 2020

(C) Springer-Verlag GmbH Germany, part of Springer Nature 2020

It is a right tradition to devote a special issue to great scientists on the occasion of an anniversary. It gives an excellent opportunity to express our respect as a sign of high esteem to the honoured person for an outstanding scientific career and their achievements. Therefore, it is appropriate that we celebrate the 65 th birthday of Professor Fritz Scholz with this Festschrift who absolutely deserves such an appreciation. However, in this case there is another important point. He has to be honoured not only for his pre-eminent scientific activity but also for creation of the Journal of Solid State Electrochemistry. He was the founding father of it, back in 1997, and it is also his merit that the journal has become one of the leading journals in electrochemistry due to his enthusiastic and competent work as its Editor-in-Chief during the last 24 years.

It is always a profound lesson to résumé the path of life of a successful scientist.

Fritz Scholz was born in 1955; he started his higher education studies of chemistry at Humboldt University, Berlin; he obtained a Dr. rer. nat. and a Dr. sc. nat. (habilitation) from that university; and since 1993 he has worked as a tenured C3 Professor of applied analytical chemistry and environmental chemistry there. From 1998 he has been working as the Chair of analytical and environmental chemistry (C4 Full Professor) at the University of Greifswald, Germany. In 1987 and 1989, he worked with Alan M. Bond as Gordon Research Fellow at the Deakin University in Australia.

György Inzelt

inzeltgy@caesar.elte.hu

Antonio Doménech-Carbó

Antonio.Domenech@uv.es

1 Department of Analytical Chemistry, University of Valencia, Dr. Moliner, 50, 46100 Burjassot, Valencia, Spain

2 György Inzelt, Department of Physical Chemistry, Institute of Chemistry, Eötvös Loránd University, Pázmány Péter sétány 1/A, Budapest 1117, Hungary
He has been a Visiting Professor all around the world, e.g. at the Pavel Jozef Šafarik University (Kosice, Slovakia), at the Pontificia Universidad Católica de Valparaíso (Chile) and at the University of Warsaw (Poland), as well as Visiting Lecturer at the Universidad de Santiago de Chile, at the Eötvös Loránd University (Budapest, Hungary), at the Universidade Federal de Santa Maria (Brazil), at the CECRI (Karaikudi, India), at the Al-Farabi Kazakh National University (Almaty, Kazakhstan) and at the Polytechnical University (Tomsk, Russia).

He has participated at more than 300 conferences; he has been an invited speaker at more than 125 occasions. He was elected a Fellow of the International Society of Electrochemistry in 2015.

Fritz is an eminent and innovative Researcher in the field of electrochemistry and electroanalysis. He has published more than 320 scientific and several other papers and received more than 11,000 citations and has an h-index of 62. He is the Editor and a Co-author of the books Electroanalytical Methods (Springer, 2002, 2nd ed. 2010, and Russian Edition: BINOM, 2006) and Electrochemistry of Immobilized Particles and Droplets (Springer 2005) and Co-editor of the Electrochemical Dictionary (Springer, 2008; 2nd ed. 2012), volumes 7a and 7b of the Encyclopedia of Electrochemistry (Wiley-VCH 2006) and Handbook of Reference Electrodes (Springer, 2013).

Besides the Journal of Solid State Electrochemistry, he has founded the journal ChemTexts-The Textbook Journal of Chemistry (Springer Nature) in 2014 which introduced a completely new concept in scientific publishing, as it provides texts for educational purposes that reflect the current state of knowledge, not - or didactically not adequately - covered by textbooks. With so far 19 titles published since 2007, he is the committed Editor of the series Monographs in Electrochemistry (Springer) in which modern topics of electrochemistry, covering both theory and applications, are presented.

Fritz has deep interest in the history of science. He has published several original and very good articles on the 
history of electrochemistry and electroanalytical chemistry and designed and edited an excellent book: Electrochemistry in a Divided world: Innovations in Eastern Europe in the 20th Century (Springer, 2015). Fritz is also a pioneer of novel direction in the studies of history of electrochemistry: he initiated special research related to women in electrochemistry. $\mathrm{He}$ recently initiated and co-edited the first English translation of Wilhelm Ostwald's autobiography, originally published in German (Springer, 2017).

He has often proved owing a sixth sense for new scientific ideas and also the endurance to work those out. The success of various activities of Professor Scholz is based on his very rare ability to attract and to unite people. He has also a special gift to combine different talents and personal features for successful team work. It is not typical for many leaders and requires special respect.

Among the many notable results, perhaps the most salient achievement of Professor Scholz was the elaboration of the technique "Voltammetry of Immobilized Microparticles" for studying the electrochemistry of solid compounds and materials. This simple, yet genuine technique that was initially named "Abrasive Stripping Voltammetry" only requires a minimum of technical prerequisites, but it opened up new vistas in the electroanalysis of solid samples spanning from archaeological objects (metals, alloys, pigments) to minerals. Beside of its analytical importance, it made possible to investigate phase and phase transitions of solid materials.

Narrow gauge science (due to a sad trend of compartmentalisation in science or funding policy) was always a horror to him. If needed, he could cross those borders, in order to put the new ideas into practice. He introduced three-phase electrodes to determine the Gibbs energies of ion transfer between immiscible liquids. Addressing the global carbon dioxide problem with a sound proposal of "permanent wood sequestration" some years ago sparked a highly controversial discussion in the science community. In the recent years, he has been studying the interaction of free oxygen radicals with metal surfaces, as well as the interaction of liposomes with the surface of mercury electrodes in order to assess membrane properties. The recent articles related to microbial fuel cells are among his most cited papers.

Beside his never weakened inquisitiveness in research, Fritz is a motivated and skilled Teacher. Many generations of his students appreciate his enthusiastic lectures together with the seldom ability to "explain science", i.e. to "translate" even complex topics into understandable - yet correct — data. The textbook Chemical Equilibria in Analytical Chemistry (Springer 2019), co-authored by him, is a recent outcome to be named. He co-initialised a completely new course of degree programme of Environmental Sciences, as well as the formation of the new Institute of Biochemistry at Greifswald University, to shape the profile of the former Chemistry Department towards interdisciplinary biochemistry research.
More than 200 years ago, Caspar David Friedrich, who was born in Greifswald, painted his masterpiece "Der Wanderer über dem Nebelmeer" ("Wanderer above the Sea of Fog") which is a romantic view of our position in front of the nature. A historian, John Lewis Gaddis, wrote about this painting as follows: "It's impossible to know whether the prospect facing the young man is exhilarating, or terrifying, or both". We are convinced that Fritz could take up with that challenge: As a scientist, he was able to dispel the fog in the areas of his research, and - as the fog lifted — making things perfectly clear.

The Romantics favoured intuition and emotion over the rationalism. However, Fritz can combine the intuition with rationalism.

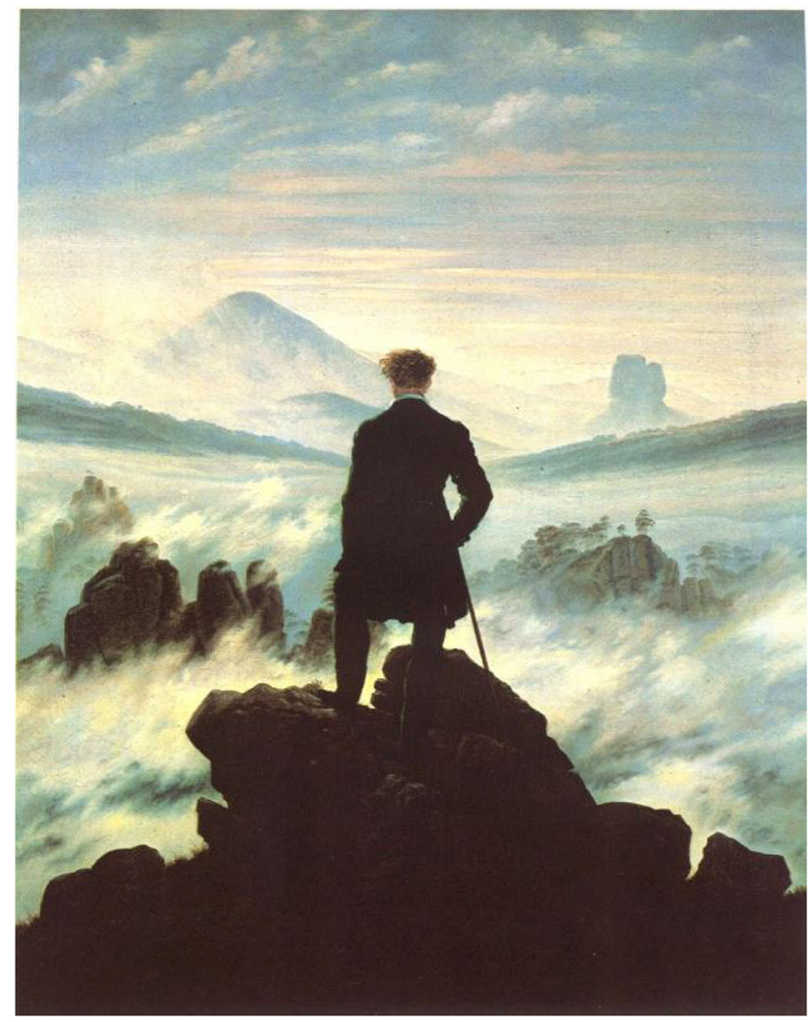

Wanderer above the Sea of Fog (1818). Kunsthalle Hamburg

Many of us have had the true privilege to enjoy his exceptional hospitality in Greifswald, working together with him, or participating at the conferences organized by him. The most characteristic qualities of Fritz are the helpfulness and respect towards other people based on his wisdom and humanism.

Fritz's multifaceted discoveries, his excellent books and papers are (and surely will be in future) a continuous source of knowledge and inspiration for generations of researchers and students.

We hope that Professor Scholz will be very pleased to see the present collection of papers of his colleagues from all around the world, his former students, postdocs and co- 
workers who have been inspired by him in his laboratory, listening to his lectures at conferences or just enjoy a conversation with him. On behalf of the community of electrochemists and electroanalytical chemists, we pay tribute to Professor Fritz Scholz.

Many happy returns of the day! 